\section{Service robots, agency and embarrassing service encounters}

\author{
Valentina Pitardi \\ Department of Marketing, University of Portsmouth, Portsmouth, UK \\ Jochen Wirtz \\ Department of Marketing, National University of Singapore, Singapore, Singapore \\ Stefanie Paluch \\ School of Business and Economics, RWTH Aachen University, \\ Aachen, Germany, and \\ Werner H. Kunz \\ Department of Marketing, University of Massachusetts, Boston, Massachusetts, USA
}

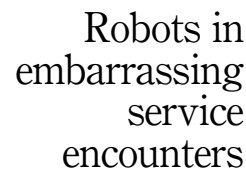

389

Received 3 December 2020 Revised 21 April 2021 21 July 2021

16 August 2021

Accepted 17 August 2021

\begin{abstract}
Purpose - Extant research mainly focused on potentially negative customer responses to service robots. In contrast, this study is one of the first to explore a service context where service robots are likely to be the preferred service delivery mechanism over human frontline employees. Specifically, the authors examine how customers respond to service robots in the context of embarrassing service encounters.

Design/methodology/approach - This study employs a mixed-method approach, whereby an in-depth qualitative study (study 1) is followed by two lab experiments (studies 2 and 3).

Findings - Results show that interactions with service robots attenuated customers' anticipated embarrassment. Study 1 identifies a number of factors that can reduce embarrassment. These include the perception that service robots have reduced agency (e.g. are not able to make moral or social judgements) and emotions (e.g. are not able to have feelings). Study 2 tests the base model and shows that people feel less embarrassed during a potentially embarrassing encounter when interacting with service robots compared to frontline employees. Finally, Study 3 confirms that perceived agency, but not emotion, fully mediates frontline counterparty (employee vs robot) effects on anticipated embarrassment.

Practical implications - Service robots can add value by reducing potential customer embarrassment because they are perceived to have less agency than service employees. This makes service robots the preferred service delivery mechanism for at least some customers in potentially embarrassing service encounters (e.g. in certain medical contexts).
\end{abstract}

Originality/value - This study is one of the first to examine a context where service robots are the preferred service delivery mechanism over human employees.

Keywords Service robots, Artificial intelligence, Agency, Embarrassment, Service encounter

Paper type Research paper

(C) Valentina Pitardi, Jochen Wirtz, Stefanie Paluch and Werner H. Kunz. Published by Emerald Publishing Limited. This article is published under the Creative Commons Attribution (CC BY 4.0) licence. Anyone may reproduce, distribute, translate and create derivative works of this article (for both commercial and non-commercial purposes), subject to full attribution to the original publication and authors. The full terms of this licence may be seen at http://creativecommons.org/licences/by/4.0/ legalcode

The authors are grateful to the guest editor Arne De Keyser and the two anonymous reviewers who provided valuable feedback and guidance to earlier versions of this article. Furthermore, this research was presented at the following meetings and conferences: the Research Seminar Series, Marketing Department at King's College Business School (London, April 2021), the 50th European Marketing Conference (May, 2021), the 2021 AMS Virtual Annual Conference (June, 2021), the 2021 Frontiers in Service Conference (July, 2021) and the 2021 AIRSI conference (July, 2021). The authors are grateful to the organizers and participants for the lively discussions, comments and ideas generated during and after the presentations. All authors contributed equally to this article.

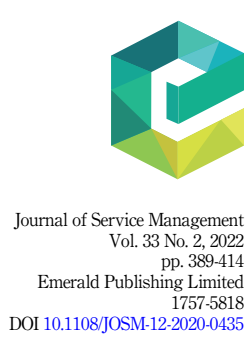


JOSM

33,2

390

\section{Introduction}

Service robots powered by artificial intelligence (AI) are increasingly common and are expected to replace or complement human service providers in numerous industries (McLeay et al., 2021; Wirtz et al., 2018; Xiao and Kumar, 2021; Yoganathan et al., 2021). For example, chatbots and virtual assistants provide banking services (e.g. Jaime, ANZ bank's digital assistant; Bornet et al., 2021) and medical advice to patients (Caić et al., 2019; Yoon and Lee, 2018), and embodied service robots (e.g. Nao and Pepper) are used in hospitality to provide information and room service (e.g. Tung and Au, 2018; Murphy et al., 2019). Given these early successes of service robot deployment, there is growing interest in expanding the use of robotics and virtual assistants in an increasing range of service contexts (Davenport et al., 2020; Grewal et al., 2020; Huang and Rust, 2021; Jörling et al., 2019; Meyer et al., 2020). However, the infusion of service robots fundamentally changes the nature of service encounters, and understanding customer interactions with service robots is important yet still under-researched (Kunz et al., 2018; Kunz and Walsh, 2020; Lu et al., 2020).

While managers are excited about the potential upsides of service robots in terms of their scalability and end-to-end customer service process automation (Bornet et al., 2021; Mustak et al., 2021), it is interesting to note that consumer research has focused mostly on negative customer responses to service robots. These include robots triggering negative attitudes (Kim et al., 2019), compensatory responses (e.g. increasing food intake to compensate feelings of discomfort; Mende et al., 2019) and purchase abandonment (Luo et al., 2019). Little is known about the beneficial characteristics of service robots that might make them the preferred service delivery mode over the traditional human-to-human encounter.

In this article, we advance that the lack of perceived agency and emotion (Ward et al., 2013; Lu et al., 2020) can potentially be beneficial in certain encounters. Agency and emotion are generally used by individuals to ascribe mind to inanimate objects (Waytz et al., 2010b). When entities are perceived as having mind (Gray and Wegner, 2012), they are usually seen as being able to act with intentions, form opinions and make moral and social judgements (i.e. have agency) and feel and sense (i.e. have emotion; Gray et al., 2007; Gray et al., 2012). Robots are typically seen as lacking intentions and feelings (Wirtz et al., 2018) and as such are unable to form opinions and make moral and social judgements (Waytz et al., 2014; van der Woerdt and Haselager, 2019). The absence of such abilities may be beneficial for those consumption settings where the presence of service employees can be detrimental to the consumers' experience as may be the case, for example, in potentially embarrassing service encounters (Grace, 2009).

Consumer embarrassment is a widespread emotion particularly relevant from a managerial perspective as it may lead consumers to avoid purchasing services (Grace, 2007). Being a social emotion (Krishna et al., 2019), embarrassment is elicited when a social transgression is witnessed by others and individuals are concerned about how others may perceive or think about them (Dahl et al., 2001). This is particularly relevant for service encounters, where customer mishaps can lead to embarrassing situations (Grace, 2007, 2009; Kilian et al., 2018), and where the products and services involved may be viewed as embarrassing (e.g. purchase of condoms, pharmacist advising on genital fungal cream and medical treatment for erectile dysfunction; Blair and Roese, 2013; Dahl et al., 2001; Iacobucci et al., 2002; Krishna et al., 2015). Service providers can adopt strategies to alleviate the degree of embarrassment for their customers. For instance, they can allow customers to shop in private (Esmark et al., 2017). Yet, there are service encounters such as specific medical services where embarrassment is almost inevitable, at least for some customers (Grace, 2007).

The aim of this article is to explore customer-service robot interactions in the context of embarrassing service encounters. Specifically, by building on the service robot literature (McLeay et al., 2021; Wirtz et al., 2018; Xiao and Kumar, 2021) and mind perception (Gray and Wegner, 2012; Gray et al., 2007), this article investigates whether the use of service robots can 
reduce customer embarrassment in otherwise potentially embarrassing service encounters. This article makes the following three contributions.

First, this research adds to the literature on customer perceptions of service robot attributes. Specifically, it is one of the first studies to examine the low perceived mind characteristic of service robots (i.e. their perceived low level of agency and inability to feel emotions; Gray et al., 2007). Our study shows that this characteristic is not only perceived by customers but that it can influence their service experience and subsequent responses.

Second and related to the first point, this study connects the embarrassment literature (Dahl et al., 2001; Krishna et al., 2019) and theories on mind perception (Gray and Wegner, 2012; Gray et al., 2007) to the emerging field of service robots. Specifically, our study shows that service robots can mitigate customers' anticipated embarrassment because they are perceived as having low agency and are therefore not able to form thoughts, opinions and judgements.

Finally, extant research has focused mostly on potentially negative customer responses to service robots. In contrast, this study is one of the first to explore a service context, where customers can benefit from the introduction of service robots and may even prefer service robots over service employees (c.f., Huang and Rust, 2018, 2021; Wirtz et al., 2018).

\section{Theoretical background and literature review \\ Service robots}

Definition and description. Previous research provided various definitions of frontline service robots. Čaic et al. (2019, p. 463) focused on physically embodied social robots and emphasized their ability to engage with users on a social level, defining them as "fully or partially automated technologies that co-create value with humans through their social functionalities". De Keyser et al. (2019, p. 163) in their frontline service technology infusion model identified embodied service robots and voice assistants as conversational agents able to "engage in social conversation with its users". Adopting a broader perspective that includes both virtual and physical representation of robots, Blut et al. (2021, p. 632) defined service robots as autonomous service agents that can be "physically embodied or virtual (for example, voice or text-based chatbots)". These definitions emphasize the social and interactive functionalities of service robots while highlighting their ability to perform autonomous tasks.

Given our focus on the use of such technologies in service provision and at the customer interface, we use the definition of service robots by Wirtz and colleagues that includes a wider spectrum of robots representation: "Service robots are system-based autonomous and adaptable interfaces that interact, communicate and deliver service to an organization's customers" (Wirtz et al., 2018, p. 909). System-based refers to service robots being connected to a company-wide system and databases and being able to learn from past interactions and even those that take place in parallel and potentially across the world. Consequently, service robots do not need to have all information stored in their physical enclosure or local system as they can retrieve information from the company's databases, CRM systems and even the Internet where applicable. Such system-wide information can actively enable, influence, customize and personalize the human-machine interaction. The system-based aspect of modern robots blurs the lines between physical and virtual robots in the service context. Traditionally, physical robots needed to have all the tools, programmes and data installed into the unit that are necessary to fulfil their tasks. Today, a physical service robot can rely on the same infrastructure virtual service robots are using (e.g. using cloud-based natural language processing for speech recognition or customizing their behaviour based on CRM data). Especially for robots that are specified for conversational tasks (e.g. welcoming, consultation and advice), the difference between physical and virtual robots is often just 
JOSM

33,2

392

limited to the visual appearance of the customer interaction interface. One example is the personal assistant service Alexa by Amazon. The consumer can decide if they want to use the service via an app on the smartphone, a physical device like a smart speaker or a physical robot with the name VECTOR. Adaptability refers to the capability of a robot to learn and adjust its behaviour based on past task performances automatically. For example, a cleaning robot stops running in the same direction if there is a barrier, and a chatbot stops asking a question if the answer is not resolvable. Autonomous indicates that a robot can do it tasks independently and is not controlled by a human employee during the service delivery process. Autonomous and adaptability are today mainly enabled by AI algorithms and increasingly will be driven by machine learning.

Service robots are designed to communicate, interact and deliver service to customers (Choi et al., 2020). In contrast to other forms of frontline technology, service robots are able to deliver interactive services and can therefore be considered service agents (McLeay et al., 2021). Service robots gain these capabilities by relying on a range of technologies (e.g. natural language processing, computer vision, machine learning and smart work flows; Bornet et al., 2021) that have AI at their core. Moreover, their social and interactive capabilities distinguish service robots from traditional self-service technologies (SSTs; Belanche et al., 2020). Service robots are powered by AI which allows them to accommodate more flexible interactions and service scripts (Lu et al., 2020), and they can even recover from service failure (Choi et al., 2020). However, it is important to note that as technology advances, future SSTs are likely to become AI-infused (c.f., Wirtz and Zeithaml, 2018) and therefore, will become smarter and more interactive than today's traditional SSTs. In this sense, the different types of service technologies can be positioned along a continuum of various degrees of intelligence and interactive flexibility that range from traditional "dumb" and not interactively flexible SSTs to smart and fully flexible interactive service robots.

Services tasks provided by service robots. Huang and Rust (2018) specified four types of intelligence required for service tasks (i.e. mechanical, analytical, intuitive and empathetic intelligence) depending on the nature of the service and identify the roles AI agents and humans can play in accomplishing those tasks. For example, the service robot Pepper is employed in restaurants, hotels, airports and hospitals to greet guests and help them navigate the servicescape (Blut et al., 2021), which are largely mechanical tasks (c.f., Huang and Rust, 2018). Recent and more advanced versions of service robots are capable of sophisticated analytical activities and can be found in professional services such as financial auditing and medical services, where, for example, chatbots are used to dispense medical advice (O'Hear, 2017; Lu et al., 2020).

While service robots have become highly effective in performing tasks that require mechanical and analytical intelligence, they mostly are deployed for transactional services and less so for relational ones, which tend to also require intuitive and empathetic intelligence (Huang and Rust, 2018). This is consistent with a proposed hierarchy of service employee substitution by AI, where tasks that require intuitive and empathic actions would be replaced last (Huang and Rust, 2018). Similarly, Wirtz et al. (2018) advanced that service robots are better suited for cognitive-analytical tasks, whereas human service providers are preferred for more complex emotional-social tasks.

The literature largely agrees that service robots will in the near future be able to perform tasks with almost any degree of cognitive complexity achieving the third level of intuitive intelligence (Huang and Rust, 2018). Wirtz et al. (2018) also predicted that hybrid teams, composed of human service providers and service robots, will be the optimal service delivery mechanism when complex analytical and emotional skills are required. The reason is that service robots are not expected to have agency for the foreseeable future and are unlikely to be able to effectively perform tasks with high emotional and social complexities (Lu et al., 2020). This is particularly relevant for contexts, where the service quality heavily depends on 
the interpersonal skills, emotional labour and personality of frontline employees. For such services, the inability of service robots to feel and express genuine emotions reduces the overall service experience (Paluch et al., 2020).

Nevertheless, the high degree of autonomy of service robots already allows for rich interactions with people (Jörling et al., 2019) and can lead to service robots being perceived as social entities (Čaić et al., 2019; Choi et al., 2020). van Doorn et al. (2017) introduced the concept of automated social presence (i.e. the extent to which technology makes consumers feel the presence of another social entity) and highlight how this presence can influence customer responses including satisfaction, loyalty and behavioural intentions.

Influence of robot design and characteristics on consumer responses. Prior service research has focused on the general acceptance, usage and application of frontline service robots (Chuah et al., 2021; De Keyser et al., 2019; Heerink et al., 2010; Rafaeli et al., 2017; van Doorn et al., 2017; Wirtz et al., 2018), and how customer-service robot interactions are influenced by robot design and characteristics. According to Wirtz et al. (2018), service robots can take various forms, including virtual (e.g. Jamie, ANZ bank's virtual agent) and embodied (e.g. Nao) agents. Their appearance can vary from machine-like (e.g. baggage handling robots in hotels) to humanlike (e.g. Pepper), to humanoid (e.g. Sophia). A number of studies investigated, for example, how the robots' mode of interaction (e.g. text-, voice-, movementand touch-based interactions; Adam et al., 2020), level of anthropomorphic appearance (Castelo et al., 2019; Choi et al., 2020; van Pinxteren et al., 2019) and even their portrayed personality (Tay et al., 2016) affect consumer responses.

A great deal of attention has been devoted to understanding the role played by anthropomorphism in service robots (Blut et al., 2021). Research on this topic reports contrasting findings. Some scholars demonstrated that interactions with humanoid service robots elicit consumer discomfort (Mende et al., 2019) and decrease consumer attitudes toward robots due to increasing feelings of eeriness and uncanniness that arise when robots become more humanlike (Kim et al., 2019). However, recent studies showed how humanlike features such as a face, arms or a voice can positively influence consumer responses via sociocognitive evaluations (Belanche et al., 2021; Choi et al., 2020; Yoganathan et al., 2021), resulting in increased trust and enjoyment (van Pinxteren et al., 2019). While the majority of these studies have focused on the effect caused by the robots' humanlike appearance, an overlooked characteristic of service robots is their perceived lack of mind (i.e. their inability to have agency and emotion) that consumers may attribute to them.

Theories of mind, agency and emotion. Theories of mind perception hold that individuals attribute mind to both human and non-human entities along two closely related dimensions: agency (i.e. the ability to act purposely, form opinions and make moral and social judgements; Gray et al., 2012) and experience (i.e. the ability to feel emotions; Gray et al., 2007). (Note, in this article we refer to the dimension of experience as emotion to avoid confusion with other wellestablished service concepts). This stream of research suggests that while humans are seen as having both high levels of agency and emotion, robots are typically perceived as having low levels of agency and lacking emotion (Gray et al., 2007; Gray and Wegner, 2012). Importantly, agency and emotion perceptions significantly influence how individuals evaluate and respond to non-human agents (Waytz et al., 2010a, b). For example, when entities are perceived as having a higher level of agency, people tend to hold them responsible for their actions and blame them more in case of negative outcomes (Waytz et al., 2014). On the positive side, individuals tend to feel empathy toward entities that are perceived as having some level of emotion and see harming them as morally wrong (Gray and Wegner, 2012).

Drawing on theories of mind perception (Waytz et al., 2014), our study aims to shed light on this not yet researched aspect of customer interactions with service robots and examine how their low level of perceived agency and emotion may be able to mitigate feelings of embarrassment in otherwise embarrassing service encounters.

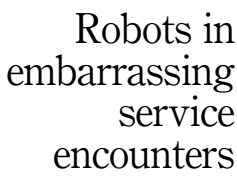

393 
JOSM

33,2

394

\section{Service embarrassment}

Service consumers can experience embarrassment across various contexts. For example, embarrassment can be triggered by awkward social service encounters (i.e. improper, inappropriate or ungraceful acts, expression of emotions and verbal blunders; Grace, 2007), consumer incompetence (Krishna et al., 2019; Wu and Mattila, 2013) and purchase of sensitive products such as condoms and erectile dysfunction medication that are viewed as inherently more embarrassing than others (Blair and Roese, 2013; Dahl et al., 2001; Iacobucci et al., 2002; Krishna et al., 2015).

The social evaluation model proposes that embarrassment stems from the perceived presence of others and their evaluations (Manstead and Semin, 1981), which makes embarrassment particularly relevant in the service encounter context (Grace, 2009). While most consumer literature on embarrassment has focused on the purchase of sensitive and embarrassing goods, only a few studies have investigated embarrassing service encounters. Notable exceptions include Grace (2007), who examined in an exploratory study the causes, dimensions and consequences of embarrassment in service encounters. This study identified three main sources of embarrassment (i.e. criticism or violations of privacy coming from the service provider, awkward acts or errors made by the customer and inappropriate behaviours displayed by others) and their potential negative consequences (e.g. reduced patronage and negative word of mouth). Focussing on consumers' mishaps in a restaurant context, Wu and Manila (2013) showed that embarrassment in service encounters increases when consumers realize their own mistake (i.e. internal flagging) and are in the presence of a large group of familiar others. Kilian et al. (2018) explored the phenomenon of vicarious embarrassment (i.e. the embarrassment experienced by an individual when others misbehave) and showed the potential negative consequences of it, including negative word of mouth, switching behaviour and store image loss. Further, Esmark et al. (2017) demonstrated that the mere perceptions of being watched by an employee during an embarrassing purchase could result in purchase abandonment because of the feeling of being judged.

In addition to the triggers of embarrassment and the role played by the perceived social presence of others (Dahl et al., 2001), previous studies examined how consumers activate various coping strategies to avoid or reduce the threat of embarrassment (Brackett, 2004). For example, consumers may decide to shop in off-peak times and in stores that are less crowded to diminish the likelihood of being the object of unwanted appraisal by others. Similarly, when consumers anticipate feeling embarrassed by a purchase, they may decide to buy additional products with the aim to mitigate the threat (Blair and Roese, 2013). Furthermore, the simple availability of a shopping basket in the store can allow customers to "hide" certain goods and feel more in control of their privacy, and thereby decrease feelings of embarrassment (Esmark et al., 2017). Out-store and in-store technologies can also decrease consumer embarrassment. For example, some embarrassing products are better sold online as it allows customers to avoid embarrassing interactions (Bailey et al., 2001). Similarly, instore technology, such as vending machines, enables consumers to minimize interactions with staff and thus reduces feelings of embarrassment. Finally, in the context of hospitality services that operate in international contexts, clear service scripts and service employee training can mitigate feelings of embarrassment due to customers potentially violating unfamiliar cultural and social norms (Mattila and Enz, 2002; Wu and Mattila, 2013).

These approaches can reduce embarrassment in many contexts, but there are service encounters where embarrassment is almost inevitable (Grace, 2007). For example, while SSTs can be used for some embarrassing products (e.g. condoms in vending machines), they are not suitable for more complex service encounters (e.g. an embarrassing medical examination). Moreover, compared to service robots, SSTs do not allow for deviations from tight service scripts, are hardly customer error tolerant (Wirtz et al., 2018) and generally cannot provide service recovery, potentially resulting in lower levels of service quality (Choi et al., 2020). In 
such more complicated service encounters, service robots can potentially help to reduce customer embarrassment.

A few studies examined service robots in potentially embarrassing service encounters. For example, Bartneck et al. (2010) provided preliminary insights into the influence of anthropomorphized robots on students' feelings of embarrassment of being weighted and measured with their clothes off. The study found that students were more comfortable when examined by a machine-like robot (technical box) rather than an anthropomorphic robot. Similarly, Choi et al. (2014) found that robots remotely controlled by humans elicited a higher level of social presence and perceptions of embarrassment than autonomous robots. Yet, little is known about the underlying psychological processes and conditions under which embarrassment in service encounters can be mitigated, especially when compared to service provided by human employees. That is, research is needed to understand the potential beneficial role service robots may play in mitigating consumer feelings of embarrassment. To provide initial insights into this topic and to guide our hypotheses development, we conducted a qualitative study as discussed next.

\section{Study 1: Qualitative interviews on embarrassment and service robots}

The purpose of this study is to explore the nature of customer embarrassment in different service contexts, and how these may change when consumers interact with service robots instead of human employees. Study 1 adopted an exploratory qualitative research design (Denzin and Lincoln, 2008; Mays and Pope, 1995) drawing on in-depth interviews (Boyce and Neale, 2006) with consumers in Western countries who had a recent embarrassing service experience. Given the sensitivity of the topic and the fact that embarrassing situations are often consciously suppressed, a research design had to be deployed that encourages interviewees to openly share their experiences. In-depth interviews were chosen as they provide "detailed information about informant's thoughts and behaviours or [and] explore new issues in depth" (Boyce and Neale, 2006, p. 3). The objectives of the exploratory study were to understand causes of embarrassment in service encounters, the sources of embarrassment, how consumers deal with the feeling and how this embarrassment can potentially be attenuated through the use of different service robot configurations.

\section{Interviews and sample}

A purposive sampling strategy was applied (Patton, 2015), whereby informants were screened to be at least 18 years old and had a recent embarrassing service experience. We approached individuals from various backgrounds to avoid potential homogeneity-related issues. In-depth interviews were conducted with 40 participants via Zoom due to COVID-19 restrictions during the conduct of this study. We used Zoom with video interface rather than just voice-based communications. The main reason was that the researcher and informants could meet virtually from the comfort of their homes and could see each other which aided in establishing personal rapport (Gray et al., 2020). Furthermore, non-verbal signals and body language could also be seen which gave the interview situation a more personal touch and relaxed atmosphere (c.f., Archibald et al., 2019). We stopped interviewing at the 40th respondent, when we reached a point of data saturation at which no significant additional insights were obtained (Boddy, 2016). Informants' age ranged from 20 to 82 years, and twothirds were female. More than half of the participants had a master's degree.

An interview guide was prepared with questions stemming from the key themes identified from the embarrassment and service literature. The guide helped to ensure that the interviews were conducted in a systematic, consistent and comprehensive manner (Patton, 2015). It consisted of an introductory and a main part. The introductory part served as an ice- 
JOSM

33,2

396

breaker and asked informants to recall a recent embarrassing service situation and reflect on their feelings and emotions during the service encounter. In the main part, informants were asked about the reasons (triggers) why they felt embarrassed and what had led to this feeling. Then, informants were asked to explain how they dealt with the embarrassment (coping strategies), whether they did anything to overcome the situation, and if yes, what it was they did. The last part of the main section was dedicated to the potential role of service robots in embarrassing encounters. Informants were asked to imagine that they had interacted with a service robot instead of a human employee in their embarrassing encounter. Then, they were asked to elaborate on how this might have changed their perceptions and feelings. Those participants who already had experience with service robots in potentially embarrassing service encounters were asked to what extent the use of robots instead of human employees had changed their perception of embarrassment. The interviews lasted between 45 and $60 \mathrm{~min}$.

Analysis

All interviews were recorded and transcribed verbatim. Transcripts were read to ensure their correctness and then imported into NVivo, a qualitative data analysis software platform. Similar to prior qualitative research in marketing (e.g. Davis et al., 2011), the interview data were subjected to thematic analysis (Braun and Clarke, 2006), which began with three of the authors independently coding the raw data (Campbell et al., 2013; O'Connor and Joffe, 2020).

Thematic analysis is suitable to discover emerging themes within the raw data, and it helps to describe the data in detail (Braun and Clarke, 2006). To achieve this in our study, the thematic analysis involved six phases. After getting familiar with the data (phase 1), the textual data were analysed line-by-line to identify relevant codes based on the actual language used by the informants (phase 2). In phase 3 , the codes were summarized into broader themes. These codes were then reviewed by the team and transferred into a coding map (phase 4). The thematic structure was developed in the context of critical discussion and reflection with the authors, which involved regular meetings to check reliability and consistency, and to resolve discrepancies. In phase 5, themes were refined and structured. See Figure 1 for a pictorial presentation of the findings. The final phase 6 consisted of writing the results, describing the different sections of the framework and integrating supporting quotations from the interviews.

Next, we discuss human service employees and different types of service robot configurations (see Figure 1, left column) in the context of potentially embarrassing service encounters. Then, we examine the reasons why and how service robots can potentially mitigate embarrassment.

\section{Service employees, service robot configurations and consumer embarrassment}

The findings show that informants perceived different levels of embarrassment when interacting with service employees vs various types of service robot configurations. First, almost all informants reported that the highest level of embarrassment was felt when interacting with human service employees. As illustrated by the following quotes, the key reason for this finding was that informants never knew what employees were thinking and were afraid of being judged:

It was totally uncomfortable for me to talk to the employee about something so intimate. I had it in my head the whole time: "What is he thinking about me now?" How embarrassing is that . . . I was so happy when the whole situation was over. It was really stressful. (female, 28 , retail assistant)

You can tell what some employees think about you just by looking at their faces. They then grimace as if they wanted to say: "Look at them!" I find that completely unnecessary, and to avoid that embarrassing situation I would like to interact with robots. (female, 30, Ph.D. student) 


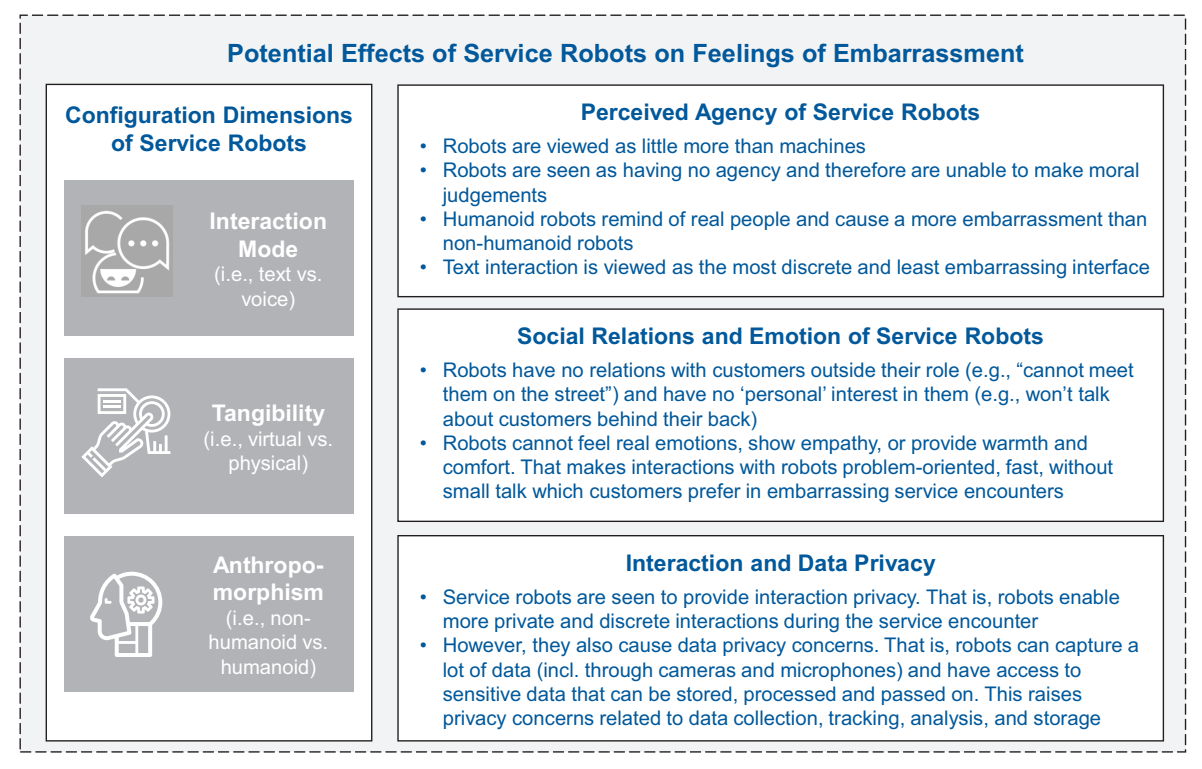

\section{Robots in embarrassing service encounters}

The good thing is the robot will not judge me. That's the big difference to humans, who sometimes gossip behind my back or roll their eyes. (female, 60, saleswoman)

The interaction with robots is very anonymous.... It is a machine, why should it be interested in me. (male, 28, engineer)

Interactions with humanoid robots were perceived as much less embarrassing than with human employees. However, between the different configurations of service robots, humanoid robots had the highest potential to cause embarrassment. Informants explained that with humanoid robots they had the impression of interacting with human beings again. That is, these robots were perceived as almost humanlike with their appearance that closely resembles humans and with facial features and eyes that follow people when they move. And it is the human aspect of these robots that was perceived as unpleasant. Therefore, we could conclude that the more human the robot was, the more embarrassment potential informants felt.

A Pepper, he has such big eyes, he already reminds me of a human being. It makes me feel insecure and I do not really feel comfortable there. If he does not understand that and afterward screams through the shop that I'm looking for haemorrhoid cream that would be really embarrassing. (male, 46, accountant).

The robots, which look very human, scare me. They are almost like humans and I would feel more uncomfortable. You never know what a robot does and how it reacts. (female, 20, student)

If the robot resembles a human, then I feel somewhat observed. (female, 60, saleswoman)

Physical robots with mechanical appearances and little resemblance to humans caused less embarrassment compared to humanoid robots. They were seen by informants as a source of information and can be compared to chatbots in terms of their embarrassment potential. The interactions took place non-verbally, whereby questions were entered via a keyboard or a touchscreen. 
JOSM

33,2

398

I once interacted with a robot at the airport. It had a big display and I could type in my question directly. I asked it where the next toilet was, and it showed me the way there on the display. That was well done and not embarrassing at all. (male, 58, business owner)

The nice thing about this machine is that I can type everything in there. No one else can see it, so I can ask anything I want. (male, 29, entrepreneur)

The perception of embarrassment when interacting with voice assistants was different. With voice control, the interaction was no longer viewed as discreet as with chatbots, and informants were afraid that the assistant would suddenly say awkward things in the presence of others:

I asked Siri something about an illness [after leaving the doctor's office] and suddenly she started talking very loudly. It was really embarrassing because I could not turn it off so quickly. (female, 28, accountant)

The voice assistants are not that good yet because they misunderstand many things and then the whole thing gets embarrassing because other people can listen. (female, 22, intern at dentist)

The least embarrassment was perceived when informants used text-based chatbots. Informants felt comfortable with chatbots as the communication was viewed as discreet and just between the robot and the customer as shown in the following quotes:

Nobody notices that when I write ... so it is all between us. I can also ask questions completely anonymously and get no silly looks from others. (male, 30 years old, salesman)

Writing questions to the chatbot is a natural thing for me. I also find it more comfortable to talk about embarrassing things or ask questions than to do that at the pharmacy, for example, when other customers are standing behind me. (female, 28 , retail assistant)

In summary, it can be concluded that the feeling of embarrassment was the highest when informants interacted with human service employees. Furthermore, embarrassment also varied with different types of service robot configurations based on their appearance (humanlike robots lead to more embarrassment than machine-like ones) and mode of interaction (voice-based interactions were perceived as more embarrassing than text-based ones). In the next section, we explore possible reasons why service robots may lead to less embarrassment compared to human employees.

\section{Reasons service robots reduce consumer embarrassment}

Three main themes emerged from the interviews that explain why service robots can lead to lower levels of embarrassment. In particular, compared to human service employees, service robots are perceived to (1) lack agency and judgement, (2) have less social and emotional relations and (3) have interactive privacy advantages but also data-related privacy risks.

Perceived lack of agency. Informants described service robots as little more than machines. Almost all of them agreed that it is the lack of agency that is the greatest difference between robots and human employees and which leads to less embarrassment. Informants did not feel judged and did not feel the need to justify their behaviours to service robots. Furthermore, robots were perceived as not knowing what behaviour is right or wrong, and what is socially acceptable as shown in the following quotes:

I do not need to justify my behaviour in front of a machine. With a human being you always have the pressure to explain yourself. (male, 29, owner of a start-up)

I think with the robot it is all about the problem [at hand]. Humans might think something and then judge [me]. (female, 28, consultant) 
Machines do not think, they are programmed to fulfil their task. When we interact with people, there is always a human factor. This brings the human touch, for example, through facial expressions, gestures or social feedback, and this might also include embarrassing moments. (male, 33, health consultant)

Embarrassment is typically related to what others may think of a person. Informants felt that employees have opinions about their customers, may judge and think badly about them. Therefore, informants explained that they do not care so much about what service robots think of them, but that this would be different with human employees.

He [robot] will not think: What kind of a crazy guy is this? (male, 33, health consultant).

When I signed up for physical therapy for my knee, I was already uncomfortable. I am overweight, I know that myself. I am also aware that my overweight is largely the cause of my knee problems, but what should I do? I think that the therapists are judging me, but no one is really saying it. A robot like that would not care. I am sure of that. (female, 60 , saleswoman)

For the robot it does not matter what I buy or what I have done. It will not judge me for it or point its finger at me. (female, 82 , retired)

Informants believed that service robots, unlike humans, deal with customer needs discreetly as shown in the following quote:

After the operation, I had to be supported while walking. The nurse had to struggle with me, and from time to time she moaned a bit. When I imagine a robot like that, he will not complain about my weight. They simply have to be solidly built. (female, 60, saleswoman)

Low social and emotional relations. Informants mentioned the lower or even non-existent social and emotional relations they had with service robots as an important reason that reduced their feelings of embarrassment.

I imagine a visit to a robot doctor as less embarrassing. I have no history with the robot, the robot does not know me personally and I will not meet him again somewhere on the street. This is really only about the problem I have. I also know that I cannot expect any empathy from a robot when it tells me my diagnosis. But that is ok. (female, 28, retail assistant)

I know the woman since I was a child, so I was really embarrassed to be counselled by her. (male, 20, student)

Also, the interaction with service robots was described as more discreet compared to those with human employees. In addition, robots were seen as less intrusive than humans (i.e. robots are not curious), which is a characteristic that many informants appreciated:

What bothers me about the employees is that they are really annoying sometimes and make the situation even worse for me with their stupid and sometimes nasty questions. Robots will be less interested in me and my story and where I got the STD from. Robots ... will not be so annoying. (female, 22, intern at dentist)

I personally find robots more discreet than employees ... robots do not bitch about me behind my back. (male, 44, lawyer)

Informants considered service robots as machines without a soul, meaning that they did not expect understanding or social relations from robots. The interactions with service robots were characterized by a strong problem focus. Service robots were viewed as being designed to help customers, and this was perceived to happen without small talk or the usual polite phrases to start a conversation and signal interest in the other person. Also, informants did not expect warmth, comfort or empathy from robots. For embarrassing situations, informants preferred this neutral, less emotional and less personal interaction:

\section{Robots in embarrassing service encounters}


JOSM

33,2

Especially in embarrassing situations you want it to be over quickly. With a robot, you do not have to talk about personal matters or general small talk. I think it's really good and I would rather go to a robot with an embarrassing topic. (male, 20, student)

I do not run the risk of being recognized by a robot and asked about my problems. People generally want to have a conversation, perhaps to express interest, and that then very quickly becomes very personal. (female, 35 , project manager)

Perceived privacy advantages and concerns. The role of privacy with service robots seemed to be a double-edged sword. During the service encounter, service robots were viewed as offering enhanced privacy. Specifically, informants described robots as discreet service counterparties, where the customer retains sufficient anonymity during a potentially embarrassing service encounter. As a result, informants would rather interact with robots in embarrassing situations because the interaction is seen as more anonymous and offers higher interaction privacy:

Well, I have to say that with a robot I think I am in good hands. Our conversation is confidential, and the robot does not know who he is talking to. So I feel quite comfortable and think my privacy is quite well protected. (female, 30 , nurse)

It does not get any more anonymous than that. It does not feel embarrassing to me, but quite the opposite. It's quick and there's no need for embarrassing conversations with [an] employee. (male, 27, engineer)

However, not all informants saw just a positive privacy impact when dealing with service robots. Some informants viewed robots as a technology that often has cameras and microphones and can record, analyse, store and pass on data and conversations. Especially in embarrassing situations, informants wanted to prevent this kind of information from being stored for a long time or from being associated with their person.

You read a lot in the media about what robots can do and that they spy on us. So when I imagine that they can store and retrieve all my data, that's really scary. And if it also says that she bought 200 condoms last year ... wow, this is really embarrassing. I do not know what else happens to the data? (female, 35, teacher)

I assume that with a service employee I am the hundredth customer today, then he has quickly forgotten me, but a robot does not forget. And that is the thing that makes me feel uncomfortable. (male, 27, engineer)

I prefer to talk about these very intimate things with an employee whom I can also trust. Then, I'm sure that my information will not be passed on. (female, 79, retired)

At this point, we can conclude that robots cause less embarrassment because there is no agency attributed to them. At the same time, our informants appreciate the discreet interaction and show understanding that robots cannot truly establish social and emotional relationships. It is these missing judgemental and social aspects that lead to less embarrassment for the informants.

Nevertheless, informants showed paradoxical behaviour with regard to privacy, and therefore, we distinguish two different types of privacy for service robots - namely interaction and data privacy. On the one hand, informants appreciate the anonymous interaction with robots (interaction privacy), which causes less embarrassment for them since interacting with robots appears to be more discreet. On the other hand, informants worry about their data privacy when interacting with service robots due to the intrusiveness of technology (e.g. cameras and microphones), plus they do not know what happens to their data.

Based on the findings of study 1 , attribution of agency and emotion to service robots seem to represent potentially important factors that can reduce feelings of embarrassment. We 
next integrate our study 1 findings with the extant literature to develop our research hypotheses for the testing in studies 2 and 3 .

\section{Hypotheses development: service robots and mind perception}

Past research in psychology and social robotics has investigated the process of perceptions of mind in non-human agents (e.g. technology, nature and animals) and objects (e.g. people's possessions). It found that the tendency of ascribing mental states to non-human agents influences individuals' behaviours, judgements and decisions (Gray and Wegner, 2012; Waytz et al., 2010a, b; Waytz and Young, 2014). The research on human-robot interaction has mostly focused on specific design features and examined how humanlike features and traits, such as the presence of eyes and whether the robot has a humanoid body, influence the extent to which people anthropomorphize robots (Abubshait and Wiese, 2017; van der Woerdt and Haselager, 2019). While a humanlike appearance can foster perceptions of mind, studies from social psychology showed that the mere perception of mental states in a non-human object is not just a necessary but also a sufficient condition for perceived humanness (Morewedge et al., 2007; Waytz and Young, 2014).

Perceptions of mind are elicited through perceptions of agency and emotion (Gray et al., 2007). In terms of agency, service robots are generally perceived as not having autonomous intentions nor the ability to form opinions and make moral and social judgements (Russell and Norvig, 2010; Ward et al., 2013; van der Woerdt and Haselager, 2019). In terms of emotions, service robots are not able to have real feelings, at least not for the foreseeable future (Wirtz et al., 2018; Paluch et al., 2020). Recent studies have demonstrated that although humanoid robots (e.g. Sophia) are able to emulate a wide range of facial expressions, individuals do not recognize emotions in them (Chuah and $\mathrm{Yu}, 2021$ ). In other words, one can assume that humans do not attribute intentionality and emotion to a service robot, and thus would view them as unable to morally or socially judge one's behaviours. Therefore, it seems reasonable to expect that during an embarrassing service encounter, consumers' level of anticipated embarrassment will decrease when interacting with a service robot (vs a human service employee).

Further, we predict that this effect will be mediated by the global perceptions about service robot's ability to act with intention, form opinions, make moral and social judgements (i.e. have agency), and experience emotions (Gray and Wegner, 2012). Specifically, we expect that consumers will attribute a lower level of mind (i.e. agency and emotion) to robots (c.f., Wirtz et al., 2018), and this, in turn, will reduce anticipated embarrassment. Accordingly, we summarize our discussion in Figure 2 and propose:

H1. During a potentially embarrassing service encounter, interactions with a service robot (vs a human employee) decrease consumers' anticipated embarrassment.

H2. The reduced level of anticipated embarrassment when served by a service robot (vs a human employee) is mediated by perceptions of mind, that is, perceptions of agency (H2a) and emotion (H2b).

\section{Study 2: Testing the base model \\ Method, design and procedure}

To test our hypotheses, we conducted two online scenario-based experiments. Study 2 tested the base model effect of service robots on consumers' anticipated embarrassment compared to service employees (H1). Study 3 extended the base model and examined the hypothesised underlying mediation effect of mind perception and its two dimensions of agency (H2a) and emotion (H2b).

Respondents in study 2 were told to imagine that they had an appointment in a medical clinic, and that they had to provide the receptionist with preliminary information about their

\section{Robots in embarrassing service \\ encounters}


JOSM

33,2

402

Figure 2.

Conceptual model

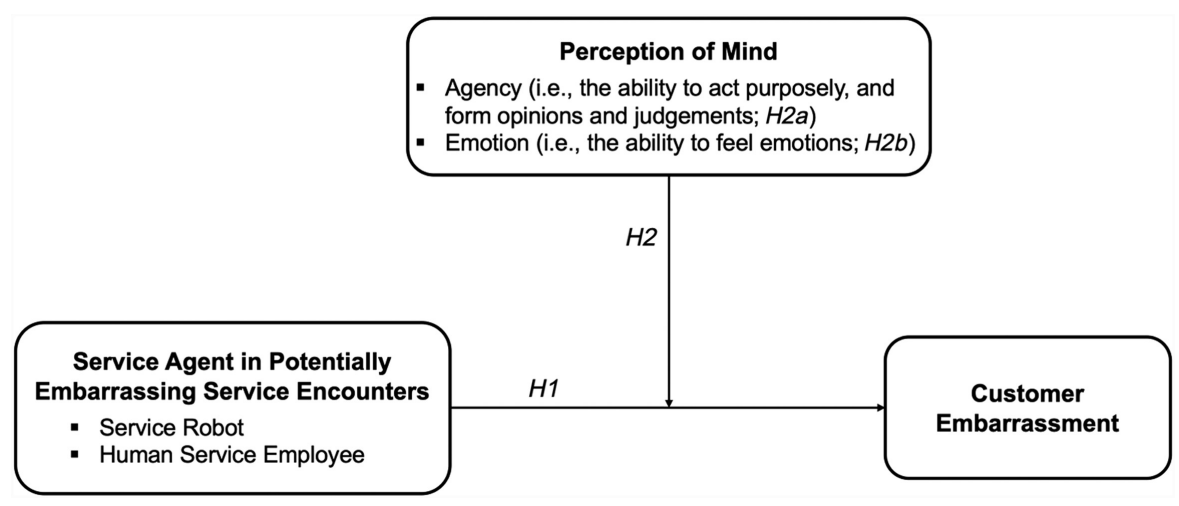

condition. To manipulate the level of embarrassment, participants in the embarrassing condition were told to imagine that they suffered from haemorrhoids (embarrassing condition) or gastritis (not embarrassing condition), and that they had to describe their condition to the receptionist. The frontline agent was manipulated by showing either a picture of a human receptionist or a service robot (see Appendix for sample scenarios). The manipulations followed previous studies on embarrassment (Blair and Roese, 2013; Dahl et al., 2001) and service robot encounters (Mende et al., 2019). Then, the dependent variable of anticipated embarrassment was measured. Finally, respondents answered to demographic and scenario-related questions to control for gender, age, novelty and familiarity (Blair and Roese, 2013; Mende et al., 2019). The measurement scales are shown in Table 1 . All measures display good reliability (i.e. Cronbach alpha values of 0.79 or higher).

Pre-test

A pre-test was conducted with a separate group of respondents $(n=50)$ from the same study 2 population to validate the scenario manipulations. First, pre-test respondents rated their anticipated embarrassment on the three-item scale $(\alpha=0.87)$ used in the main study. Specifically, participants rated how embarrassed, uncomfortable and awkward they would feel in the described situation (Dahl et al., 2001). An analysis of variance (ANOVA) showed that, as intended, the embarrassing scenario was rated as significantly more embarrassing than the not embarrassing scenario $\left(M_{\text {high_embarr }}=5.51, \mathrm{SD}=1.68\right.$ vs $M_{\text {low_embarr }}=2.17$, $\mathrm{SD}=1.50 ; F[1,49]=65.2, p<0.001)$. Further, the robot/human employee manipulation revealed that the service robot was perceived as more machine-like compared to the human receptionist $\left(M_{\text {robot }}=5.18, \mathrm{SD}=1.61\right.$ vs $M_{\text {human }}=2.63, \mathrm{SD}=1.37 ; F[1,165]=119.9$, $p<0.001$ ). Thus, these findings suggest that the manipulations were effective.

\section{Sample}

For the study 2 proper, a total of 166 participants ( $M_{\text {age }}=33.7 ; 66.3 \%$ female) were recruited through Prolific, a professional agency that specializes in respondent recruitment. Respondents were randomly assigned to our experimental conditions in a 2 (service robot vs human employee) $\times 2$ (high embarrassment vs low embarrassment service encounter) between-subject design.

\section{Hypothesis testing}

To test H1, we conducted a two-way ANOVA. The results showed a significant main effect of the frontline service assistant on anticipated embarrassment, whereby respondents expected 


\begin{tabular}{|c|c|c|c|}
\hline \multirow[b]{2}{*}{ Scale items } & \multicolumn{2}{|c|}{ Scale reliability } & \multirow[b]{2}{*}{ References } \\
\hline & & & \\
\hline $\begin{array}{l}\text { Perceived machine-likeness } \\
\text { - The receptionist/pharmacist is like a person } \\
\text { - The receptionist/pharmacist is machine-like }\end{array}$ & $r=0.87$ & $r=0.92$ & Mende et al. (2019) \\
\hline $\begin{array}{l}\text { Agency } \\
\text { - The pharmacist in the story can think } \\
\text { - The pharmacist in the story can plan its actions } \\
\text { - The pharmacist in the story can exercise self-control } \\
\text { - The pharmacist in the story can form opinions }\end{array}$ & - & $\alpha=0.82$ & $\begin{array}{l}\text { Adapted from Gray and } \\
\text { Wegner (2012) }\end{array}$ \\
\hline $\begin{array}{l}\text { Emotion } \\
\text { - The pharmacist in the story can experience pleasure } \\
\text { - The pharmacist in the story can have desires } \\
\text { - The pharmacist in the story can be happy } \\
\text { - Tory can feel pain }\end{array}$ & - & $\alpha=0.93$ & $\begin{array}{l}\text { Adapted from Gray and } \\
\text { Wegner (2012) }\end{array}$ \\
\hline $\begin{array}{l}\text { Perceived embarrassment } \\
\text { How would do you feel in this situation: } \\
\text { - } 1=\text { ="not embarrassed at all", and } 7=\text { "extremely } \\
\text { embarrassed" } \\
\text { - } 1=\text { ="not uncomfortable at all", and } 7=\text { "extremely } \\
\text { uncomfortable" } \\
\text { - } 1=\text { "not awkward at all", and } 7=\text { "extremely } \\
\text { awkward" }\end{array}$ & $\alpha=0.91$ & $\alpha=0.91$ & $\begin{array}{l}\text { Dahl et al. (2001), Blair } \\
\text { and Roese (2013) }\end{array}$ \\
\hline $\begin{array}{l}\text { Perceived novelty of the service } \\
\text { - I have not been to a medical practice/pharmacy like this } \\
\text { before } \\
\text { - This medical service/pharmacy is unusual }\end{array}$ & $\alpha=0.79$ & $\alpha=0.90$ & Mende et al. (2019) \\
\hline $\begin{array}{l}\text { Familiarity } \\
\text { - How familiar are you with this type of service? } \\
\text { Anchored in } 1=\text { "not familiar at all", } 7=\text { "very } \\
\text { familiar" }\end{array}$ & - & - & Blair and Roese (2013) \\
\hline
\end{tabular}

Note(s): Scale reliability refers to Cronbach's Alpha $(\alpha)$ for scales with three items or more and Pearson Correlation Coefficient $(r)$ to scales with two items. Unless otherwise specified, all scales used 7-point Likerttype scales anchored in $1=$ "strongly disagree" and $7=$ "strongly agree"

Table 1. Scales used in studies 2 and 3

to feel less embarrassed when interacting with a robot receptionist rather than a human receptionist $\left(M_{\text {robot }}=3.38, \mathrm{SD}=1.66\right.$ vs $M_{\text {human }}=4.93, \mathrm{SD}=1.56 ; F[1,162]=42.0$, $p<0.001)$. Most importantly, the analysis revealed a significant interaction effect between the embarrassing condition and the type of frontline agent $(F[1,162]=9.8 ; p=0.002)$. Planned contrasts showed that subjects who were exposed to the high embarrassment condition reported significantly lower feelings of anticipated embarrassment when interacting with a $\operatorname{robot}(M=3.97, \mathrm{SD}=1.47)$ than a human receptionist $(M=6.05, \mathrm{SD}=1.00 ; F[1,162]=39.1$; $p<0.001$; see Table 2). Furthermore, interactions with a robot (vs human receptionist) led to slightly lower feelings of anticipated embarrassment also in the low embarrassment condition $\left(M_{\text {robot }}=3.07, \mathrm{SD}=1.68\right.$ vs $\left.M_{\text {human }}=3.80, \mathrm{SD}=1.15 ; F[1,162]=6.8 ; p<0.05\right)$. Finally, and as expected, the increase in embarrassment between the low and high embarrassment condition was significantly higher for frontline employees $\left(\Delta M_{\text {low/high }}\right.$ embarrassment $=2.25, \mathrm{SE}=0.27, p<0.001)$ than for service robot $\left(\Delta M_{\text {low }} /\right.$ high embarrassment $=0.89, \mathrm{SE}=0.33, p<0.01$ ).

None of the control variables reached significance on the anticipated embarrassment (gender: $p=0.43$; age: $p=0.74$; novelty: $p=0.24$; familiarity: $p=0.90$ ). The significant two-way interactions combined with the analyses of planned contrast supports $\mathrm{H} 1$, 
JOSM

33,2

\begin{tabular}{lcrrrr} 
& \multicolumn{5}{c}{ Anticipated embarrassment } \\
Independent variables & df & MS & \multicolumn{1}{c}{$F$} & \multicolumn{1}{c}{$p$} & $\eta^{2}$ \\
\hline Service encounter (SE) & 1 & 95.17 & 52.9 & $<0.001$ & 0.24 \\
Frontline service assistant (FLA) & 1 & 75.49 & 42.0 & $<0.001$ & 0.20 \\
SE* FLA & 1 & 17.62 & 9.8 & 0.002 & 0.05 \\
\hline
\end{tabular}

404

Contrasts

SE

Table 2.

Study 2: ANOVA

results and planned

simple contrasts for

hypotheses testing

High embarrassment

Low embarrassment

High vs low embarrassment

High vs low embarrassment

FLA

df

$\Delta$

Robot vs human

$1-2.07$

Robot vs human

Robot

Human

-2.07
-0.72
0.89

2.25

\begin{tabular}{rll}
\multicolumn{1}{c}{$F$} & \multicolumn{1}{c}{$p$} & $\eta^{2}$ \\
39.1 & $<0.001$ & 0.19 \\
6.8 & $<0.05$ & 0.04 \\
7.2 & $<0.01$ & 0.04 \\
66.1 & $<0.001$ & 0.29
\end{tabular}

suggesting that interactions with a service robot decrease feelings of embarrassment (see Figure 3).

\section{Study 3: Testing the mediating effects of agency and emotion}

Sample, design, and method

Study 3 was conducted to investigate the mediating role of mind perception (i.e. agency in $\mathrm{H} 2 \mathrm{a}$ and emotion in H2b). A sample of 121 respondents ( $M_{\text {age }}=27.6 ; 57.0 \%$ female) was recruited through Prolific. Respondents were randomly assigned to one of the two experimental conditions (i.e. service robot vs human employee), both set in an embarrassing service context. Specifically, to create an embarrassing service encounter, participants were instructed to imagine that following a medical visit they had to go to a pharmacy to collect the prescribed anti-fungal treatment for genitals. The frontline agent was manipulated by showing either the picture of a human pharmacist or that of a service robot (see Appendix). The same scales as in study 2 were used to measure anticipated embarrassment, robotic style, familiarity and novelty, while agency and emotion were measured using an eight-item scale

Figure 3.

Findings of study 2

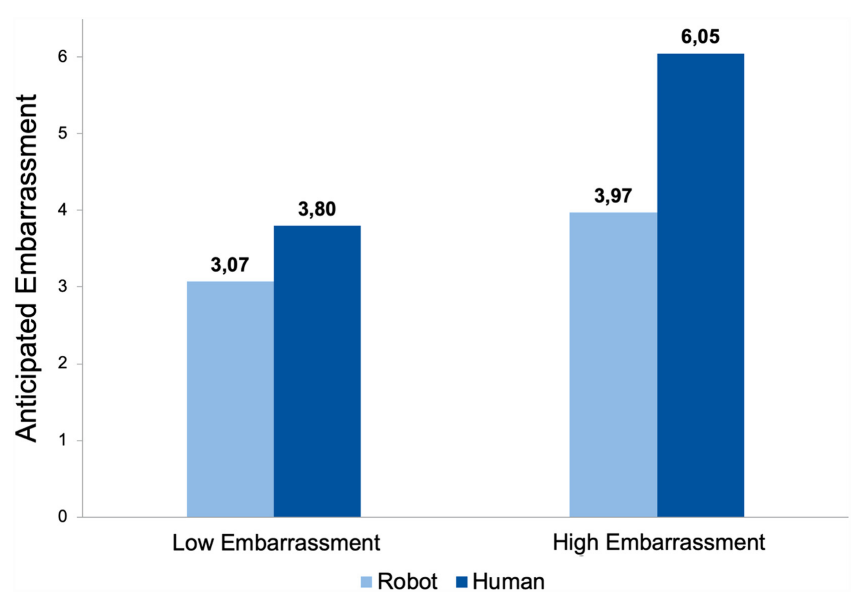


adapted from Gray and Wegner (2012). See Table 1 for the scale items and Cronbach alpha values.

\section{Manipulation check and scale reliability}

First, we checked the validity of our manipulation. As expected, participants rated the service robot as more machine-like compared to the human pharmacist $\left(M_{\text {robot }}=5.93, \mathrm{SD}=1.37 \mathrm{vs}\right.$ $\left.M_{\text {human }}=2.45, \mathrm{SD}=1.38 ; F[1,120]=189.2, p<0.001\right)$. Further, all scales showed good reliability with correlation coefficients or Cronbach alpha values of 0.82 or higher.

\section{Hypothesis testing}

First, the base model of study 2 was replicated. A one-way ANOVA of frontline service assistant (service robot vs human) on anticipated embarrassment showed that respondents expected to feel less embarrassed when collecting the medication from a service robot pharmacist compared to a human pharmacist $\left(M_{\text {robot }}=2.97\right.$ vs $M_{\text {human }}=4.09$; $F[1,120]=13.3, p<0.001)$, confirming the hypothesised main effect of the type of frontline assistant on anticipated embarrassment (H1).

To test the mediating role of perceived agency and emotion on customer anticipated embarrassment (H2a, H2b), we employed PROCESS SPSS macro Hayes (2017), using the mediation model (Model 4), whereby the frontline assistant (i.e. robot vs service employee) served as the independent variable, perceived agency and emotion as mediators, and anticipated embarrassment as the dependent variable. To test the mediation of total and indirect effects, we adopted the recommended bootstrapping technique (sample size of 5,000 for the bias corrected bootstrap confidence intervals).

The direct effects of the frontline assistant on agency $(b=-1.77, \mathrm{SE}=0.24,95 \% \mathrm{CI}$ $[-2.26,-1.28])$ and emotion $(b=-3.54, \mathrm{SE}=0.21,95 \% \mathrm{CI}[-3.97,-3.11])$ are significant, meaning that respondents attributed less mind to service robots (i.e. less agency and less emotion). The impact of perceived agency on anticipated embarrassment is significant $(b=0.31, \mathrm{SE}=0.16,95 \% \mathrm{CI}[0.01,0.64])$, while the effect of emotion is not significant $(b=$ $-0.19, \mathrm{SE}=0.18,95 \% \mathrm{CI}[-0.57,0.17])$. Furthermore, frontline assistant type (i.e. robot vs employee) is no longer significant when controlling for the mediators $(b=-0.66, \mathrm{SE}=0.56$, $95 \%$ CI [-1.7, 0.45]), indicating full mediation.

We conducted two separate indirect effect analyses to further examine agency and emotion individually. The findings confirm the mediating role of perceived agency $(b=0.32$, $\mathrm{SE}=0.10,95 \% \mathrm{CI}[0.03,0.39])$ but not emotion $(b=0.07, \mathrm{SE}=0.12,95 \% \mathrm{CI}[-0.17,0.32])$. None of the controls reached significance. That is, there were no gender $(p=0.38)$, age $(\phi=0.52)$, novelty $(\phi=0.83)$ and familiarity $(\phi=0.25)$ effects in any of the predicted models.

Overall, these results suggest that frontline service assistant type (i.e. service robot vs human employee) exerts its indirect effect on customer anticipated embarrassment only through perceived agency (H2a) but not emotion (H2b), thus providing support for H2a but not $\mathrm{H} 2 \mathrm{~b}$.

\section{Discussion and conclusions}

Service robots are expected to become increasingly common in our daily service encounters (Puntoni et al., 2021). Extant research has focused on the role of service robots in the broader context of service management (Wirtz et al., 2018) and the negative responses of customers to the introduction of service robots (Kim et al., 2019; Mende et al., 2019). However, past research provides little guidance on how service robots can be deployed to enhance the overall customer experience (Kunz et al., 2018, 2019). The present study examines a context in which service robots are likely to be the preferred delivery mechanism over people-provided service.

\section{Robots in embarrassing service \\ encounters}


JOSM

33,2

Specifically, it shows that the low level of agency attributed to service robots can reduce customer feelings of embarrassment in otherwise potentially embarrassing service encounters.

\section{Theoretical implications}

This research contributes to the growing literature on service robots by identifying perceived agency as a central construct that influences customer perceptions and behaviours. Consistent with previous research, we found that people attribute no or only low levels of agency and emotion to service robots (Bigman and Gray, 2018; Gray and Wegner, 2012). Furthermore, we found that this perceived low level of agency (i.e. their inability to act intentionally, form opinions and make moral and social judgements) is the main reason why consumers feel less embarrassed when interacting with a robot. Previous studies have shown that the more service robots are capable of mimicking humanlike abilities and behaviours, the more consumers will develop stronger connections with them (van Pinxteren et al., 2019). Our findings suggest the opposite in potentially embarrassing service encounters and reveal potential beneficial consequences of low levels of agency and robots not being humanlike.

Our study bridges the literature on embarrassment (Dahl et al., 2001; Grace, 2009) and mind perception (Gray and Wegner, 2012; Waytz et al., 2010a, b) to the emerging field of service robots (Huang and Rust, 2021; Wirtz et al., 2018; Xiao and Kumar, 2021) and demonstrates that it is the lack of service robots' agency that mitigates the negative consequences of an otherwise embarrassing service encounter. This finding further enhances our understanding of consumer embarrassment by recognizing agency as a new relevant factor (c.f., Grace, 2007, 2009). While previous studies have demonstrated that embarrassment is dependent on the mere presence of others, be it real or imagined (Blair and Roese, 2013; Dahl et al., 2001; Krishna et al., 2019), our findings show that it is their agency that causes embarrassment.

The qualitative study 1 examined the impact of service robot configuration (i.e. their interaction mode, tangibility and anthropomorphism) on embarrassment. The results suggest that tangible and humanlike robots can unfavourably affect consumer embarrassment because of their resemblance with humans, while robots in the form of chatbots and virtual agents were considered more suitable for embarrassing interactions. These results echo previous research on anthropomorphism negatively influencing consumer responses (Castelo et al., 2019; Kim et al., 2019; Mende et al., 2019) and contribute to the current debate as to what constitutes the optimal level of human likeness of service robots by uncovering additional potential negative consequences of higher anthropomorphism (De Keyser et al., 2019).

Finally, a paradoxical role of privacy arose from our qualitative study. On the one hand, informants valued the interactive privacy robots provide during the actual service encounter. They described robots as discreet interlocutors and depicted the interactions with them as more anonymous and neutral. On the other hand, and consistent with previous conceptual work (Lobschat et al., 2021; Wirtz et al., 2018), for some informants, data privacy emerged as a potential deterrent for interacting with service robots. Service robots are by nature able to record, process and store information from the surroundings and the interactions they have. This ability results in higher data privacy and security concerns, especially when sensitive and embarrassing information is involved. These findings advance our understanding of the role of privacy in customer-service robot interactions (Caić et al., 2018; Pitardi and Marriott, 2021) and show that robots may provide customers with more interaction privacy but less data privacy. 


\section{Managerial implications}

This study provides further insights into customer-service robot interactions and adds to the question of which tasks and actions can, and perhaps should be, executed by service robots (Davenport et al., 2020; De Keyser et al., 2019). Our study identified potentially embarrassing service encounters as a service context where robot deployment can be beneficial for consumers by reducing their feeling of embarrassment.

The underlying mechanism that reduces embarrassment is the low level of perceived agency of service robots. There is an ongoing debate on how much robots should not only look but also behave humanlike. However, by identifying agency as a relevant factor influencing consumer-service robot interactions, our findings suggest that marketers should focus not only on anthropomorphism but also on agency to better understand the best fit between specific service contexts and robot design. In particular, our findings suggest that service managers should encourage the deployment of service robots with a low level of perceived agency in potentially embarrassing service encounters. Here, robots are effective in providing more comfortable customer experiences while delivering a more convenient and interactive experience compared to otherwise prefer SST's.

For example, we found that text-based robots (e.g. chatbots) are the customers' preferred delivery mode in potentially embarrassing service encounters, while humanoid (e.g. Sophia) and humanlike robots (e.g. Pepper) appear as less suitable because of their appearance. Given this, service managers could adapt the type of service robot configurations to specific service contexts and deploy less humanlike robots in situations where customers may experience embarrassment (e.g. body measurements and examinations in medical clinics).

Finally, our study shows that consumers value and appreciate the level of interaction privacy and anonymity that service robots can offer during the actual service encounter. However, at the same time, customers display concerns about the privacy of their personal data. To mitigate data security concerns, firms should follow and communicate to customers their adoption of best practices in data privacy and corporate digital responsibility (c.f., Lobschat et al., 2021; Wirtz and Lwin, 2009).

\section{Further research and limitations}

In this study, we investigated how perceptions of service robots' mind influence consumer responses in embarrassing service encounters. We found that perceptions of a low level of agency, but not emotion, decrease customer feelings of embarrassment. These findings and our study's limitations open up promising avenues for future research.

First, we examined customer reactions to service robots in a specific service context (i.e. potentially embarrassing medical services) using hypothetical scenarios. Future studies should examine other service contexts to strengthen the external validity of our findings. Potential research contexts could be wine sommelier services for the uninitiated or guests on a budget (e.g. "can you recommend a good bottle for less than $\$ 100$ ?") or education services for people who should know the topic at hand but do not. Also, service robots are becoming ubiquitous, and future studies should perform field experiments investigating actual consumers-robot interactions rather than using hypothetical scenarios.

Second, while our qualitative study shows that the configuration of robots is a factor that influences the feeling of embarrassmentj, we did not empirically test for differences in robot appearance (e.g. more or less humanlike), tangibility (e.g. virtual vs physical robots) and interaction mode (e.g. text vs voice). Would consumers feel less embarrassed when interacting with a chatbot rather than a voice-based or an embodied robot? For example, studies from the human-computer interactions literature showed that individuals tend to feel more comfortable and less ashamed to reveal sensitive personal information about themselves when online, for instance when chatting or using email, because of perceptions

\section{Robots in embarrassing service \\ encounters}


JOSM

33,2

408 of anonymity (Suler, 2005). These insights raise the question of whether the degree of humanlikeness and tangibility of the service robot influence feelings of embarrassment. We also found that embodied service robots trigger higher perceptions of mind. Future research could explore whether distinct types of robot configurations in terms of appearance and interaction mode could elicit different perceptions of mind, which in turn lead to differences in customer responses.

Third, the inability of service robots to form opinions and judge customers may be advantageous in a range of other contexts, where consumers can have unpleasant selfconscious emotions such as guilt, shame and shyness. For example, customers in a restaurant could feel less shy to send an unsatisfactory dish back when a service robot is assisting them. Future research could explore if the effect of low perceived agency holds benefits in the mitigation of other negative emotions beyond embarrassment.

Forth, in our qualitative study, we identified the inability to feel real emotions and develop emotional connections and advanced this in $\mathrm{H} 2 \mathrm{~b}$ as one of the potential reasons why service robots can decrease customer embarrassment. However, study 3 did not provide support for the mediating role of emotion on anticipated embarrassment. This insignificant effect could potentially be explained by the relational nature of the emotional dimension that emerged from our interviews. According to our informants, a relevant factor in embarrassing encounters with robots is the lack of emotional and social connection between service robots and customers. The impossibility to have a relation with customers outside their role of service agent (e.g. a customer will not accidently bump into the clinic's robot at the local grocery store) and the absence of interest in the customers' personal life are the social and emotional characteristics that can make robots the preferred option in embarrassing encounters. While in the experimental studies, we measured the ability of the robot to have feelings and emotions, we did not give these emotions meaning to the customer and capture the interpersonal and relational dimension which remains to be done in future research.

Furthermore, and related to the previous point, failure of robots to display true emotions could potentially be useful in specific service contexts such as funeral parlours, where customers may benefit from neutral, low emotionally charged interactions. Research so far has emphasized potential negative impact of robots' lack of emotions (Huang et al., 2019); future studies should also investigate how the reduction or even absence of emotion can improve customers' service experiences in specific contexts.

Fifth, our qualitative study sheds new light on individuals' perceptions of privacy with service robots and revealed that while our informants valued the anonymity that robots can offer during a service interaction, they also displayed concern about their data privacy. It would be interesting to explore the differential drivers of interaction privacy and data privacy and their impact on consumer behaviour. Future research could explore this topic, especially given the current debate on privacy issues related to the use of AI agents (c.f., Lobschat et al., 2021).

Finally, our study focused on Western countries. As culture has been identified as an important factor influencing perceptions of embarrassment (Grace, 2007; Kilian et al., 2018), replications in other cultures may be promising. For example, it has been shown that embarrassment can vary across collectivist (i.e. Eastern) and individualist (i.e. Western) cultures in relation to how the self is construed. Specifically, interdependent self-construal and generally collectivist cultures (e.g. China and Japan) display greater concerns for their public image and higher embarrassability (Krishna et al., 2019), which suggest that our findings may prove even more relevant in Eastern cultures. Thus, further research is needed to examine and compare the effects of service robot's low perceived mind on embarrassment and other unpleasant self-conscious emotions such as guilt and shame.

In conclusion, we suggest that service robots can be the preferred service delivery mechanism over human employees in embarrassing service encounters. It is easy to see the downsides of change, and the current literature has uncovered many potential negative 
consumer responses to service robots. In contrast, our study is a first step to appreciate better the potential consumer benefits when interacting with service robots. We feel that this is an exciting new perspective and hope that our study contributes to a growing stream of research on this topic.

\section{References}

Abubshait, A. and Wiese, E. (2017), "You look human, but act like a machine: agent appearance and behavior modulate different aspects of human-robot interaction", Frontiers in Psychology, Vol. 8, p. 1393.

Adam, M., Wessel, M. and Benlian, A. (2020), "AI-based chatbots in customer service and their effects on user compliance", Electronic Markets, Vol. 9 No. 2, pp. 1-19.

Archibald, M.M., Ambagtsheer, R.C., Casey, M.G. and Lawless, M. (2019), "Using zoom videoconferencing for qualitative data collection: perceptions and experiences of researchers and participants", International Journal of Qualitative Methods, Vol. 18, pp. 1-8.

Bailey, J.J., Gremler, D.D. and McCollough, M.A. (2001), "Service encounter emotional value: the dyadic influence of customer and employee emotions", Services Marketing Quarterly, Vol. 23 No. 1, pp. 1-24.

Bartneck, C., Bleeker, T., Bun, J., Fens, P. and Riet, L. (2010), "The influence of robot anthropomorphism on the feelings of embarrassment when interacting with robots Paladyn", Journal of Behavioral Robotics, Vol. 1 No. 2, pp. 109-115.

Belanche, D., Casaló, L.V., Flavián, C. and Schepers, J. (2020), "Robots or frontline employees? Exploring customers' attributions of responsibility and stability after service failure or success", Journal of Service Management, Vol. 31 No. 2, pp. 267-289.

Belanche, D., Casaló, L.V., Schepers, J. and Flavián, C. (2021), "Examining the effects of robots' physical appearance, warmth, and competence in frontline services: the humanness-valueloyalty model”, Psychology and Marketing, pp. 1-20.

Bigman, Y.E. and Gray, K. (2018), "People are averse to machines making moral decisions”, Cognition, Vol. 181, pp. 21-34.

Blair, S. and Roese, N.J. (2013), "Balancing the basket: the role of shopping basket composition in embarrassment", Journal of Consumer Research, Vol. 40 No. 4, pp. 676-691.

Blut, M., Wang, C., Wünderlich, N.V. and Brock, C. (2021), "Understanding anthropomorphism in service provision: a meta-analysis of physical robots, chatbots, and other AI", Journal of the Academy of Marketing Science, Vol. 49, pp. 632-658.

Boddy, C.R. (2016), "Sample size for qualitative research", Qualitative Market Research: An International Journal, Vol. 19 No. 4, pp. 426-432.

Bornet, P., Barkin, I. and Wirtz, J. (2021), Intelligent Automation: Welcome to the World of Hyperautomation, World Scientific Books, Hackensack, NJ.

Boyce, C. and Neale, P. (2006), Conducting In-Depth Interviews: A Guide for Designing and Conducting In-Depth Interviews for Evaluation Input, Pathfinder International, Watertown.

Brackett, K.P. (2004), “College students' condom purchase strategies”, The Social Science Journal, Vol. 41 No. 3, pp. 459-464.

Braun, V. and Clarke, V. (2006), "Using thematic analysis in psychology", Qualitative Research in Psychology, Vol. 3 No. 2, pp. 77-101.

Čaić, M., Mahr, D. and Oderkerken-Schröder, G. (2019), "Value of social robots in services: social cognition perspective”, Journal of Services Marketing, Vol. 33 No. 4, pp. 463-478.

Čaić, M., Oderkerken-Schröder, G. and Mahr, D. (2018), "Service robots: value co-creation and codestruction in elderly care networks", Journal of Services Management, Vol. 29 No. 2, pp. 178-205. 
JOSM

33,2

Campbell, J.L., Quincy, C., Osserman, J. and Pedersen, O.K. (2013), “Coding in-depth semistructured interviews: problems of unitization and intercoder reliability and agreement", Sociological Methods and Research, Vol. 42 No. 3, pp. 294-320.

Castelo, N., Schmitt, B. and Sarvary, M. (2019), "Human or robot? Consumer responses to radical cognitive enhancement products", Journal of the Association for Consumer Research, Vol. 4 No. 3, pp. 217-230.

Choi, J.J., Kim, Y. and Kwak, S.S. (2014), "Are you embarrassed? The impact of robot types on emotional engagement with a robot", Proceedings of the 2014 ACM/IEEE International Conference on Human-Robot Interaction, pp. 138-139.

Choi, S., Mattila, A.S. and Bolton, L.E. (2020), "To err is human (-oid): how do consumers react to robot service failure and recovery?”, Journal of Service Research, Vol. 24 No. 3, pp. 354-371.

Chuah, S.H.W. and Yu, J. (2021), "The future of service: the power of emotion in human-robot interaction", Journal of Retailing and Consumer Services, Vol. 61.

Chuah, S.H.W., Aw, E.C.X. and Yee, D. (2021), "Unveiling the complexity of consumers' intention to use service robots: an fsQCA approach", Computers in Human Behavior, Vol. 123, forthcoming.

Dahl, D.W., Manchanda, R.V. and Argo, J.J. (2001), "Embarrassment in consumer purchase: the roles of social presence and purchase familiarity", Journal of Consumer Research, Vol. 28 No. 3, pp. 473-481.

Davenport, T., Guha, A., Grewal, D. and Bressgott, T. (2020), "How artificial intelligence will change the future of marketing", Journal of the Academy of Marketing Science, Vol. 48 No. 1, pp. 24-42.

Davis, D.F., Golicic, S.L. and Boerstler, C.N. (2011), "Benefits and challenges of conducting multiple methods research in marketing", Journal of the Academy of Marketing Science, Vol. 39 No. 3, pp. 467-479.

De Keyser, A., Köcher, S., Alkire, L., Verbeeck, C. and Kandampully, J. (2019), "Frontline service technology infusion: conceptual archetypes and future research directions", Journal of Service Management, Vol. 30 No. 1, pp. 156-183.

Denzin, N.K. and Lincoln, Y.S. (Eds), (2008), Handbook of Critical and Indigenous Methodologies, Sage, Los Angeles, California.

Esmark, C.L., Noble, S.M. and Breazeale, M.J. (2017), "I'll be watching you: shoppers' reactions to perceptions of being watched by employees", Journal of Retailing, Vol. 93 No. 3, pp. 336-349.

Grace, D. (2007), "How embarrassing! An exploratory study of critical incidents including affective reactions", Journal of Service Research, Vol. 9 No. 3, pp. 271-284.

Grace, D. (2009), "An examination of consumer embarrassment and repatronage intentions in the context of emotional service encounters", Journal of Retailing and Consumer Services, Vol. 16 No. 1, pp. 1-9.

Gray, H.M., Gray, K. and Wegner, D.M. (2007), "Dimensions of mind perception”, Science, Vol. 315 No. 5812, p. 619.

Gray, K. and Wegner, D.M. (2012), "Feeling robots and human zombies: mind perception and the uncanny valley", Cognition, Vol. 125 No. 1, pp. 125-130.

Gray, K., Young, L. and Waytz, A. (2012), "Mind perception is the essence of morality", Psychological Inquiry, Vol. 23 No. 2, pp. 101-124.

Gray, L.M., Wong-Wylie, G., Rempel, G.R. and Cook, K. (2020), "Expanding qualitative research interviewing strategies: zoom video communications", The Qualitative Report, Vol. 25 No. 5, pp. 1292-1301.

Grewal, D., Kroschke, M., Mende, M., Roggeveen, A.L. and Scott, M.L. (2020), "Frontline cyborgs at your service: how human enhancement technologies affect customer experiences in retail, sales, and service settings", Journal of Interactive Marketing, Vol. 51, pp. 9-25.

Hayes, A.F. (2017), Introduction to Mediation, Moderation, and Conditional Process Analysis: A Regression-based Approach, Guilford Publications. 
Heerink, M., Kröse, B., Evers, V. and Wielinga, B. (2010), "Relating conversational expressiveness to social presence and acceptance of an assistive social robot", Virtual Reality, Vol. 14 No. 1, pp. 77-84.

Huang, M.H. and Rust, R.T. (2018), “Artificial intelligence in service”, Journal of Service Research, Vol. 21 No. 2, pp. 155-172.

Robots in embarrassing service encounters

Huang, M.H. and Rust, R.T. (2021), "Engaged to a robot? The role of AI in service", Journal of Service Research, Vol. 24 No. 1, pp. 30-41.

Huang, M.H., Rust, R.T. and Maksimovic, V. (2019), "The feeling economy: managing in the next generation of artificial intelligence (AI)", California Management Review, Vol. 61 No. 4, pp. 43-65.

Iacobucci, D., Calder, B.J., Malthouse, E.C. and Duhachek, A. (2002), "Psychological, marketing, physical, and sociological factors affecting attitudes and behavioral intentions for customers resisting the purchase of an embarrassing product”, Advances in Consumer Research, Vol. 30, pp. 236-240.

Jörling, M., Böhm, R. and Paluch, S. (2019), "Service robots: drivers of perceived responsibility for service outcomes", Journal of Service Research, Vol. 22 No. 4, pp. 404-420.

Kilian, T., Steinmann, S. and Hammes, E. (2018), "Oh my gosh, I got to get out of this place! A qualitative study of vicarious embarrassment in service encounters", Psychology and Marketing, Vol. 35 No. 1, pp. 79-95.

Kim, S.Y., Schmitt, B.H. and Thalmann, N.M. (2019), "Eliza in the uncanny valley: anthropomorphizing consumer robots increases their perceived warmth but decreases liking", Marketing Letters, Vol. 30 No. 1, pp. 1-12.

Krishna, A., Herd, K.B. and Aydınoğlu, N.Z. (2015), "Wetting the bed at twenty-one: embarrassment as a private emotion", Journal of Consumer Psychology, Vol. 25 No. 3, pp. 473-486.

Krishna, A., Herd, K.B. and Aydınoğlu, N.Z. (2019), "A review of consumer embarrassment as a public and private emotion", Journal of Consumer Psychology, Vol. 29 No. 3, pp. 492-516.

Kunz, W.H., Heinonen, K., Lemmink, J. and Lucas, B. (2018), "Future service technologies: business models, analytics, and experience", Call for Papers in Journal of Services Marketing, available at: http://www.emeraldgrouppublishing.com/products/journals/call_for_papers.htm?id1/4724 (accessed 22 June 2020).

Kunz, W.H., Heinonen, K. and Lemmink, J.G.A.M. (2019), "Future service technologies: is service research on track with business reality?", Journal of Services Marketing, Vol. 33 No. 4, pp. 479-487.

Kunz, W.H. and Walsh, G. (2020), "After the revolution - new chances for service research in a digital world", Journal of Service Management, Vol. 31 No. 3, pp. 597-607.

Lobschat, L., Mueller, B., Eggers, F., Brandimarte, L., Diefenbach, S., Kroschke, M. and Wirtz, J. (2021), "Corporate digital responsibility", Journal of Business Research, Vol. 122, pp. 875-888.

Lu, V.N., Wirtz, J., Kunz, W.H., Paluch, S., Gruber, T., Martins, A. and Patterson, P.G. (2020), "Service robots, customers and service employees: what can we learn from the academic literature and where are the gaps?", Journal of Service Theory and Practice, Vol. 30 No. 3, pp. 361-391.

Luo, X., Tong, S., Fang, Z. and Qu, Z. (2019), "Frontiers: machines vs. humans: the impact of artificial intelligence chatbot disclosure on customer purchases", Marketing Science, Vol. 38 No. 6, pp. 937-947.

Manstead, A.S. and Semin, G.R. (1981), "Social transgressions, social perspectives, and social emotionality", Motivation and Emotion, Vol. 5 No. 3, pp. 249-261.

Mattila, A.S. and Enz, C.A. (2002), "The role of emotions in service encounters", Journal of Service Research, Vol. 4 No. 4, pp. 268-277.

Mays, N. and Pope, C. (1995), "Qualitative research: rigour and qualitative research”, Bmj, Vol. 311 No. 6997, pp. 109-112. 
JOSM

33,2

McLeay, F., Osburg, V., Yoganathan, V. and Patterson, A. (2021), "Replaced by a robot: service implications in the age of the machine", Journal of Service Research, Vol. 24 No. 1, pp. 104-121.

Mende, M., Scott, M.L., van Doorn, J., Grewal, D. and Shanks, I. (2019), "Service robots rising: how humanoid robots influence service experiences and elicit compensatory consumer responses", Journal of Marketing Research, Vol. 56 No. 4, pp. 535-556.

Meyer, C., Cohen, D. and Nair, S. (2020), "From automats to algorithms: the automation of services using artificial intelligence", Journal of Service Management, Vol. 31 No. 2, pp. 145-161.

Morewedge, C.K., Preston, J. and Wegner, D.M. (2007), "Timescale bias in the attribution of mind", Journal of Personality and Social Psychology, Vol. 93, pp. 1-11.

Murphy, J., Gretzel, U. and Pesonen, J. (2019), "Marketing robot services in hospitality and tourism: the role of anthropomorphism", Journal of Travel and Tourism Marketing, Vol. 36 No. 7, pp. 784-795.

Mustak, M., Salminen, J., Plé, L. and Wirtz, J. (2021), "Artificial intelligence in marketing: bibliometric analysis, topic modeling and research agenda”, Vol. 124 (January), pp. 389-404.

O'Connor, C. and Joffe, H. (2020), "Intercoder reliability in qualitative research: debates and practical guidelines", International Journal of Qualitative Methods, Vol. 19, pp. 16094069-19899220.

O'Hear, S. (2017), "Babylon health partners with UK's NHS to replace telephone helpline with AIpowered chatbot", available at: https://techcrunch.com/2017/01/04/babylon-health-partnerswith-uks-nhs-to-replace-telephone-helpline-with-ai-powered-chatbot/ (accessed 22 March 2021).

Paluch, S., Wirtz, J. and Kunz, W. (2020), "Service robots and the future of service", in Bruhn, M., Kirchgrorg, M., Barth, S. and Burmann, C. (Eds), Marketing Weiterdenken - Zukunftspfade für eine marktorientierte Unternehmensführung, 2nd ed., Springer Gabler-Verlag, pp. 423-425.

Patton, M.Q. (2015), Qualitative Research and Evaluation Methods: Integrating Theory and Practice, Sage, Thousand Oaks, California.

Pitardi, V. and Marriott, H.R. (2021), "Alexa, she's not human but ... unveiling the drivers of consumers' trust in voice-based artificial intelligence", Psychology and Marketing, Vol. 38 No. 4, pp. 626-642.

Puntoni, S., Reczek, R.W., Giesler, M. and Botti, S. (2021), "Consumers and artificial intelligence: an experiential perspective", Journal of Marketing, Vol. 85 No. 1, pp. 131-151.

Rafaeli, A., Altman, D., Gremler, D.D., Huang, M.-H., Grewal, D., Iyer, B., Parasuraman, A. and de Ruyter, K. (2017), "The future of frontline research: invited commentaries", Journal of Service Research, Vol. 20 No. 1, pp. 91-99.

Russell, S. and Norvig, P. (2010), Artificial Intelligence: A Modern Approach, 3rd ed., Pearson Prentice Hall, Upper Saddle River.

Suler, J. (2005), "The online disinhibition effect", International Journal of Applied Psychoanalytic Studies, Vol. 2 No. 2, pp. 184-188.

Tay, B.T., Low, S.C., Ko, K.H. and Park, T. (2016), "Types of humor that robots can play", Computers in Human Behavior, Vol. 60, pp. 19-28.

Tung, V.W.S. and Au, N. (2018), "Exploring customer experiences with robotics in hospitality", International Journal of Contemporary Hospitality Management, Vol. 30 No. 7, pp. 2680-2697.

van der Woerdt, S. and Haselager, P. (2019), "When robots appear to have a mind: the human perception of machine agency and responsibility", New Ideas in Psychology, Vol. 54, pp. 93-100.

van Doorn, J., Mende, M., Noble, S.M., Hulland, J., Ostrom, A.L., Grewal, D. and Petersen, J.A. (2017), "Domo arigato Mr. Roboto: emergence of automated social presence in organizational frontlines and customers' service experiences", Journal of Service Research, Vol. 20 No. 1, pp. 43-58.

van Pinxteren, M.M.E., Wetzels, R.W.H., Rüger, J., Pluymaekers, M. and Wetzels, M. (2019), "Trust in humanoid robots: implications for services marketing”, Journal of Services Marketing, Vol. 33 No. 4, pp. 507-518. 
Ward, A.F., Olsen, A.S. and Wegner, D.M. (2013), "The harm-made mind: observing victimization augments attribution of minds to vegetative patients, robots, and the dead", Psychological Science, Vol. 24 No. 8, pp. 1437-1445.

Waytz, A. and Young, L. (2014), "Two motivations for two dimensions of mind", Journal of Experimental Social Psychology, Vol. 55, pp. 278-283.

Waytz, A., Cacioppo, J. and Epley, N. (2010a), "Who sees human? The stability and importance of individual differences in anthropomorphism", Perspectives on Psychological Science, Vol. 5 No. 3, pp. 219-232.

Waytz, A., Gray, K., Epley, N. and Wegner, D.M. (2010b), "Causes and consequences of mind perception”, Trends in Cognitive Sciences, Vol. 14 No. 8, pp. 383-388.

Waytz, A., Heafner, J. and Epley, N. (2014), "The mind in the machine: anthropomorphism increases trust in an autonomous vehicle", Journal of Experimental Social Psychology, Vol. 52, pp. 113-117.

Wirtz, J. and Lwin, M.O. (2009), "Regulatory focus theory, trust and privacy concern", Journal of Service Research, Vol. 12 No. 2, pp. 190-207.

Wirtz, J. and Zeithaml, V. (2018), "Cost-effective service excellence", Journal of the Academy of Marketing Science, Vol. 46 No. 1, pp. 59-80.

Wirtz, J., Patterson, P.G., Kunz, W.H., Gruber, T., Lu, V.N., Paluch, S. and Martins, A. (2018), "Brave new world: service robots in the frontline", Journal of Service Management, Vol. 29 No. 5, pp. 907-931.

Wu, L.L. and Mattila, A. (2013), "Investigating consumer embarrassment in service interactions", International Journal of Hospitality Management, Vol. 33, pp. 196-202.

Xiao, L. and Kumar, V. (2021), "Robotics for customer service: a useful complement or an ultimate substitute?", Journal of Service Research, Vol. 24 No. 1, pp. 9-29.

Yoganathan, V., Osburg, V.S., Kunz, W.H. and Toporowski, W. (2021), "Check-in at the robo-desk: effects of automated social presence on social cognition and service implications", Tourism Management, Vol. 85, 104309.

Yoon, S.N. and Lee, D. (2018), "Artificial intelligence and robots in healthcare: what are the success factors for technology-based service encounters?”, International Journal of Healthcare Management, Vol. 29 No. 7, pp. 757-786.

\section{Appendix}

\section{Scenario used for study 2}

Service encounter scenario used to manipulate level of embarrassment:

Imagine that you are in the reception at Proforma Clinic medical centre for a visit. Unfortunately, you are recently suffering from haemorrhoids (gastritis) and, even if embarrassing (common), you want to see your doctor. Before entering the doctor's office, you need to register at the information desk and to provide preliminary information about your condition.

When you arrive at the reception desk you find your receptionist that ask you to describe your pain and discomfort in your anus (stomach) and how often you experience rectal bleeding (burning feelings).

(Note: The embarrassing condition is highlighted in bold font face, and the not embarrassing condition is shown in brackets. The bold, italic font face is shown here to highlight the manipulation but was not highlighted in the scenarios presented to respondents).

Following the scenario, a photo showing either a service robot or a human service employee was shown for the frontline service agent manipulation.

\section{Robots in embarrassing service \\ encounters}


JOSM

33,2

414

\section{Scenario used for study 3}

Scenario used to describe an embarrassing service encounter and manipulate the type of service agent:

Imagine that you are recently suffering from a bad fungal skin infection that gives you redness, skin changes and itching all over your body and face. Following a medical visit, you need to go to the nearest pharmacy to collect the prescribed anti-fungal medication. When you arrive at the reception desk you need to ask for your antifungal medication and you find the pharmacist in the picture below:

Following the scenario, a photo showing either a service robot or a human service employee was shown for the frontline service agent manipulation.

The visual stimuli will be provided upon request by the corresponding author.

\section{About the authors}

Valentina Pitardi is Senior Lecturer in Marketing at the University of Portsmouth, UK. Her research interests include the psychological underpinnings of consumer interactions with AI, e.g. service robots and smart services, digital consumer engagement, and the role of negative emotions in consumer behaviour. She publishes her research in in top quality peer-reviewed marketing journals including the Journal of Business Research, Psychology and Marketing, International Journal of Contemporary Hospitality Management, and the Journal of Service Theory and Practice. Valentina Pitardi is the corresponding author and can be contacted at: v.pitardi@surrey.ac.uk

Jochen Wirtz is Vice Dean MBA Programmes and Professor of Marketing at the National University of Singapore. He is a leading authority on services marketing and management, and his research has been published in over 200 academic journal articles, incl. in six features in Harvard Business Review. His books include Services Marketing: People, Technology, Strategy (9th edition, 2021); Essentials of Services Marketing (3rd edition, 2018); and Intelligent Automation: Welcome to the World of Hyperautomation (2021). In recognition of his excellence in research and teaching, he has received of over 50 awards including the disciplines' most prestigious award, the 2019 Christopher Lovelock Career Contributions to the Services Discipline Award. For further information see JochenWirtz.com.

Stefanie Paluch is Professor for Services and Technology Marketing at RWTH Aachen University. She is a research fellow at King's College in London and she was appointed Senior Fellow at Hanken School of Economics in Helsinki. Her research focuses on the perception and acceptance of AI, e.g. service robots and smart services, by consumers, and their implementation in an organizational context. She publishes her research in leading international journals, such as the Journal of Service Research, Journal of Business Research, Journal of Service Management, Journal of Service Marketing and the Journal of Service Theory and Practice.

Werner H. Kunz is Professor of Marketing and director of the digital media lab at the University of Massachusetts Boston. His research interests are in AI, robots, digital and social media, social networks, innovation and service research. His work has been published, amongst others, in the International Journal of Research in Marketing, Journal of Retailing, British Journal of Management, Journal of Medical Internet Research, Journal of Business Research, Journal of Service Management and Computational Statistics and has been awarded multiple times. He is founder and host of the Social Media Days at UMass Boston and current board member of the Service Research Special Interest Group (SERVSIG) of the American Marketing Association (AMA), the primary professional association of service research, with over 2,000 community members worldwide.

For instructions on how to order reprints of this article, please visit our website:

www.emeraldgrouppublishing.com/licensing/reprints.htm

Or contact us for further details: permissions@emeraldinsight.com 